\title{
El derecho a la alimentación en la Ciudad de Buenos Aires. Una mirada desde las políticas públicas*.
}

\author{
The right to adequate food in the City of Buenos Aires. A view from public \\ policies.
}

\author{
Ángeles Bermúdez** \\ Verónica Carmona Barrenechea ${ }^{* * *}$ \\ Giuseppe Messina**** \\ Laura Royo ${ }^{* * * * *}$
}

\section{Resumen}

En este trabajo se abordará el análisis de dos de los principales programas alimentarios de la Ciudad de Buenos Aires, Ticket Social y Ciudadanía Porteña. Estos serán analizados desde una perspectiva macrosocial, sobre la base de un análisis crítico de los aspectos socioeconómicos y los principales nudos problemáticos que presenta su desarrollo.

\section{Abstract}

This paper addresses the analysis of two major food programs implemented by the City of Buenos Aires, Ticket Social and Ciudadanía Porteña. They will be examined from a macro

\footnotetext{
* Artículo recibido el 27 de Septiembre de 2015. Aceptado el 1 de Diciembre de 2015.

** Integrante del Grupo de Trabajo Interdisciplinario "Derechos Sociales y Políticas Públicas", Facultad de Derecho - Universidad Nacional de Buenos Aires, Argentina.

Correo electrónico: angelesbermudez@hotmail.com

*** Integrante del Grupo de Trabajo Interdisciplinario "Derechos Sociales y Políticas Públicas", Facultad de Derecho - Universidad Nacional de Buenos Aires, Argentina.

Correo electrónico: veronica.carmonab@gmail.com

**** Integrante del Grupo de Trabajo Interdisciplinario "Derechos Sociales y Políticas Públicas", Facultad de Derecho - Universidad Nacional de Buenos Aires, Argentina.

Correo electrónico: gm.messina@gmail.com

***** Integrante del Grupo de Trabajo Interdisciplinario "Derechos Sociales y Políticas Públicas", Facultad de Derecho - Universidad Nacional de Buenos Aires, Argentina.

Correo electrónico: lauraroyo@gmail.com
} 
perspective, based on a critical analysis of their main socioeconomic characteristics and the problematic issues in their development.

\section{Palabras clave}

Derecho a la alimentación - transferencias de ingreso - CABA.

\section{Keywords}

Right to Food - Cash Transfers - CABA.

\section{Introducción}

El foco de este trabajo es el análisis de Ticket Social y Ciudadanía Porteña, dos de los principales programas alimentarios de la Ciudad Autónoma de Buenos Aires (CABA). De esta manera, se constituye el recorte geográfico de análisis en la CABA, un terreno complejo, ya que es el distrito más rico del país y al mismo tiempo presenta profundas desigualdades sociales.

El tema ha asumido suma relevancia en la Argentina, ya que el derecho a la alimentación se encuentra consagrado en diferentes instrumentos internacionales de derechos humanos con jerarquía constitucional (cfr. Art. 75 inc. 22 de la Constitución Nacional) como el Protocolo de San Salvador y el Protocolo Facultativo del PIDESC (Pacto Internacional de Derechos Económicos, Sociales y Culturales). En este marco, este artículo aporta elementos para una discusión sobre la implementación en Argentina de algunas de las Directrices Voluntarias de FAO (Organización de las Naciones Unidas para la Alimentación y la Agricultura) en apoyo de la realización progresiva del derecho a una alimentación adecuada en el contexto de la seguridad alimentaria nacional. Asimismo, constituye un nuevo insumo para la implementación de indicadores de derechos sociales a partir de la aprobación de la OEA del el Grupo de Trabajo para el análisis de los informes nacionales previstos en el Protocolo de San Salvador. En términos generales, pese a los progresos en materia de reconocimiento del derecho a la alimentación, no se ha podido avanzar en la sanción de una ley nacional marco de derecho a la alimentación $y$, por otra parte, este hecho tiene su complemento en las respuestas estatales deficitarias en las jurisdicciones locales, como se muestra en este estudio para el caso de los programas alimentarios Ciudadanía Porteña y Ticket Social implementados en la Ciudad Autónoma de Buenos Aires.

Con estas premisas, a lo largo del artículo se realizará un análisis en clave de avances y retrocesos del derecho a la alimentación en la Ciudad. En esta línea, se efectuará una descripción y análisis, de los Programas Ciudadanía Porteña (CP) y Ticket Social (TS), en el marco de los Programas de Transferencia Condicionada de Ingresos (PTCI). Asimismo, se analizaran TS y CP a la luz del derecho a la alimentación en el derecho 
internacional de los derechos humanos y en la normativa nacional argentina y local de la CABA. En ese sentido, se analizará la judicialización de estos programas mediante el análisis de acción judicial presentada por el Ministerio Público Tutelar. Finalmente, se realizará un análisis cuantitativo de estos programas en cuanto a su impacto, cobertura y la relación de los montos erogados respecto a la canasta alimentaria, en un contexto inflacionario como el actual. Por último, se esbozarán algunas líneas a modo de reflexión y cierre.

\section{Programa Ciudadanía Porteña como un paso adelante en los dispositivos de transferencias de ingresos condicionadas.}

El programa Ciudadanía Porteña es de alcance local en el ámbito de la CABA y se implementa desde el año 2006, en virtud de la Ley 1878. Entre sus objetivos, se propone aumentar el número de niños/as que asisten a la escuela y/o mejorar las condiciones de salud con la intención de reducir la pobreza y el trabajo infantil; evitar que familias caigan en condiciones de pobreza aún más extremas. Concretamente, el programa consiste en una transferencia monetaria mensual por hogar receptor que impone corresponsabilidades de educación y salud. Actualmente, el monto promedio de la transferencia ronda los $\$ 1000$, oscilando entre un valor mínimo de $\$ 445$ y un máximo $\$ 2900$. El importe promedio para los hogares en situación de indigencia es de $\$ 1237$, mientras que para los que están en situación de pobreza es de $\$ 862$ (datos de abril de 2015). ${ }^{1}$ Los hogares incluidos en el programa reciben una tarjeta destinada exclusivamente a la compra de productos alimentarios, elementos indispensables de limpieza e higiene y combustibles necesarios para la cocción, solo en algunos comercios autorizados.

En los términos de su financiación, Ciudadanía Porteña es considerado un programa clave de la política social de la CABA, ya que, en promedio, entre los años 2008-2013, el programa contó con alrededor del $34 \%$ del presupuesto total del Ministerio de Desarrollo Social, aunque con una tendencia decreciente (del 40,24\% en 2008 al 24,08\% en 2013). ${ }^{2}$ En relación con programas alimentarios prexistentes, el programa CP reemplazó al programa "Vale Ciudad" ${ }^{3}$ y subsumió bajo su órbita al programa "Apoyo

\footnotetext{
${ }^{1}$ Cfr. Informe de monitoreo de mayo 2015 (GOGEPS).

${ }^{2}$ Según las Cuentas de Inversión del Gobierno de la Ciudad Autónoma de Buenos Aires (Contaduría General).

${ }^{3}$ El objetivo del programa Vale Ciudad (en adelante VC) era incrementar el poder adquisitivo de los receptores mediante una chequera mensual a favor de los grupos familiares en situación de vulnerabilidad social, durante seis meses, prorrogables. El vale era canjeable en pequeños comercios barriales por productos de la canasta básica de alimentos.
} 
Alimentario Directo a Familias" (AADF). ${ }^{4}$ De hecho, una vez implementado el programa $C P$, en el año 2006, el Vale Ciudad fue dado de baja y sus receptores, sumados a alrededor de 60 mil familias beneficiarias del programa AADF, fueron transferidos al nuevo programa.

Al inicio de su implementación, este programa significó un paso adelante en los conceptos filosófico-políticos en la aplicación de dispositivos de gestión, y parecía un avance que comenzaba, al menos, a instalar la discusión sobre las políticas universales. Sin embargo, muchos hogares fueron excluidos y 30000 familias continuaron recibiendo las cajas AADF como sustituto y paliativo hasta tanto pudieran ingresar a Ciudadanía Porteña. En efecto, ese programa siguió en vigencia al interior de Ciudadanía Porteña para aquellas familias que no cumplían con todos los requisitos exigidos la Ley $1878 .{ }^{5}$ Posteriormente, el Programa AADF fue reemplazado por el TS.

Una explicación de estos hechos está en que luego de dos grandes operativos de inscripciones llevadas adelante en los años 2005 y 2006, el programa CP cerró el ingreso a nuevos hogares. ${ }^{6}$ De esta manera, aquellas familias que en el transcurso del período 2006-2014 se ubicaron bajo la línea de la pobreza, no se les garantizó el derecho a recibir en forma directa la prestación de $\mathrm{CP}$, sino que, por el contrario, fueron ubicados dentro de TS, un programa que garantiza una transferencia de valor mucho menor, a los fines de garantizar un piso mínimo de recursos. Finalizado ese primer periodo de inscripción de $\mathrm{CP}$, comenzó un proceso en el que se realizó una evaluación socioeconómica de los hogares que solicitaron el ingreso al programa, para establecer si el hogar aspirante cumplía con las condiciones. En 2006, se registraban inscriptos en CP 120 mil familias. Sin embargo, en ese mismo año eran solamente 56745 los receptores reales de este programa, en comparación con los 60064 receptores de AADF. ${ }^{7}$

\footnotetext{
${ }^{4}$ Creado por el Decreto 1646/02, derogado por el Decreto 800/08. El programa Apoyo Alimentario Directo a Familias tenía como objetivo brindar una caja de productos alimenticios básicos de la canasta familiar para hogares en situación de vulnerabilidad alimentaria -familias bajo la línea de indigencia; con integrantes embarazadas o desnutridos o con miembros mayores de 65 años sin jubilación y pensión. Contaba con 90 mil familias receptoras hasta la implementación del programa Ciudadanía Porteña en 2006; respondía a la demanda espontánea, su cobertura era virtualmente universal en villas y era incompatible con el programa Vale Ciudad. Se entregaba una caja a hogares de hasta tres miembros, dos cajas a hogares de cuatro a siete miembros y tres cajas a hogares con más de siete miembros.

5 Principalmente migrantes sin documentación argentina -que en aquel entonces se encontraban regularizando su documentación-y aquellas familias que no tenían dos años de residencia en la ciudad.

${ }^{6}$ Se condujeron dos operativos, uno del 28/11/2005 al 23/12/2005 y otro del 20/03/2006 al 3/04/2006.

${ }^{7}$ Esto representó el núcleo duro a partir del cual se daban las altas y bajas del programa Ciudadanía Porteña. Las altas se darían mayormente para aquellas familias beneficiarias de AADF que obtuviesen el DNI argentino y que llegaran a cumplir con el requisito de residencia de dos años. Las bajas (o la reducción del monto a otorgar) se producirían por el cruce del registro de Ciudadanía Porteña con padrones de ANSES o del Registro Nacional de Personas, etc. a los efectos de verificar si alguno de los receptores
} 
Desde un punto de vista comparativo, el programa CP se relaciona con los Programas de Transferencia Condicionada de Ingresos (PTCI) que se han convertido en América Latina, desde la década de noventa, en la principal herramienta ${ }^{8}$ y "forma de intervención de los gobiernos para atender a la población en situación de pobreza, mediante la garantía de cierto nivel básico (en general mínimo) de ingresos monetarios" (AGT 2011: 6; Rodríguez Enríquez 2011: 6). Como señala Zibecchi (2008) estos programas cuentan entre sus objetivos "el apoyo a las familias para mejorar sus condiciones de vida y la inversión en 'capital humano', a través de las responsabilidades asumidas por sus receptores en la asistencia en salud y educación. Asimismo, se caracterizan por incorporar el lenguaje de derechos humanos, exigir condicionalidades y otros elementos modernizantes que los diferenciase de sus antecesores. Además, en la mayoría de los casos, la transferencia prioriza la titularidad femenina. En este sentido, tanto CP como TS constituyen ejemplos clásicos de los PTCI. Si bien estos tipos de programas implementados en la región tienen particularidades propias (cfr. por ejemplo Cecchini y Madariaga, 2011), todos comparten características comunes. Como detalla Rodríguez Enríquez (2011): i) transferir ingresos monetarios, que en algunos casos pueden ser acompañados por otros tipos de intervenciones; ii) establecer condicionalidades para la recepción del beneficio, cuya forma más habitual es la asistencia escolar y la atención sanitaria de los hijos e hijas.

A pesar de los puntos críticos que presentan los PTCI por definición, al inicio de su implementación, el programa CP significó una innovación respecto a los programas alimentarios antecedentes. Constituyó un progreso importante que, en lugar de bienes en especie, como lo hacía el Programa AADF, la transferencia fuese de tipo monetario y que fuese erogada por medio de una tarjeta, alejando lógicas clientelares, eliminando 'intermediarios' (organizaciones civiles, punteros políticos) para la entrega de la transferencia, además de garantizar un mayor grado de libertad a las familias de disponer de sus recursos, con transferencias mayores a los programas antecesores.

El programa Ciudadanía Porteña define que ante estas transferencias monetarias a los hogares debe haber por parte de estos el cumplimiento de las corresponsabilidades, esto es, que las transferencias monetarias están condicionadas a que los niños asistan a la escuela y a que las mujeres y las familias asistan de manera obligatoria al centro de

registró el ingreso al mercado formal o realizó una apertura de cuenta bancaria, o en los casos en que el titular de la transferencia accedió a una jubilación que lo ubique por encima de la línea de pobreza, etc. Además, las bajas pueden producirse por el severo régimen de sanciones que impone el programa ante el incumplimiento de las corresponsabilidades.

8 Pautassi y Zibecchi (2009) explican que la combinación entre masividad de la cobertura, know how técnico instalado tras varios años de focalización y una transferencia directa del subsidio al destinatario representaron una triada irrebatible, que ha instalado estos programas en la región como la 'gran alternativa', a los cuales se les agrega que, de acuerdo a las evaluaciones, reducen ciertas redes de intermediación o una redefinición de las prácticas clientelares. 
salud. De no ser así, el pago de las transferencias monetarias no se realiza. ${ }^{9}$ La educación y la salud se convierten, así, de derechos, en obligaciones a cambio de la recepción de una transferencia monetaria. Ya no es el Estado el que tiene la obligación de hacer ejercitable el derecho a la educación y la salud, sino que son los ciudadanos los que están obligados, a cambio de percibir el beneficio, a ir a la escuela y al centro de salud. No es la ciudadanía la que ejerce sus derechos, sino el Estado el que obliga a la asistencia a sus servicios. Para la determinación de los receptores y el monto del subsidio se aplica un Índice de Vulnerabilidad Social, que contempla variables como ingresos, cantidad de miembros del hogar y situación laboral de sus integrantes. Este tipo de información está centralizada en el Registro Único de Beneficiarios (RUB). ${ }^{10}$

A partir del año 2008, en los casos de hogares receptores de Ciudadanía Porteña integrados por jóvenes de 18 a 25 años (a octubre de 2011 se extendió hasta los 29 años) con residencia de al menos dos años en la ciudad, se les otorga el modulo "Estudiar es Trabajar", que, a mayo de 2015, consistía en un subsidio de $\$ 530$ mensuales. El objetivo es la retención y reinserción de los jóvenes en el sistema educativo formal extendiendo el acceso a la educación y mejorando las credenciales educativas para una posterior inserción en el mercado de trabajo. Este componente contaba con 2536 receptores en ese mes de 2015 (GOGEPS 2015). ${ }^{11}$

Por otra parte, es importante subrayar que en octubre de 2013 se incorporó un nuevo componente materno infantil llamado "Primeros meses". Este está destinado a las mujeres que sean titulares o integrantes de grupos familiares receptores del CP y que se encuentren embarazadas o con niñas/os menores de un año de edad. La transferencia monetaria se encuentra sujeta al cumplimiento de controles de salud a lo

\footnotetext{
${ }^{9}$ Con la firma de una carta-compromiso (con carácter de declaración jurada) los receptores asumen la obligación de realizar controles de salud de embarazadas, niños y adolescentes del hogar; garantizar la asistencia escolar de todos los niños y adolescentes de 5 a 18 años (inclusive) brindar información sobre la composición y condiciones del hogar y sus modificaciones, etc. Es incompatible con todo tipo de contratación (directa o indirecta) en cualquiera de las dependencias del Gobierno de la Ciudad. El incumplimiento de los compromisos asumidos puede generar la suspensión parcial o total de la prestación.

${ }^{10}$ Según explica un informe de monitoreo del propio programa del año 2011 (cfr. GOGEPS), se define el monto que le corresponde a cada uno de los hogares de acuerdo al nivel de pobreza, la composición del hogar y el valor de la canasta básica alimentaria (CBA) del adulto equivalente, estimada por el INDEC en función de los requerimientos kilocalóricos, proteicos y los hábitos de consumo de la población. Además, el programa contempla la existencia de asignaciones especiales en caso de integrantes de familias en situaciones específicas, como el caso de madres embarazadas o montos específicos por integrantes según edades.

${ }^{11}$ Una cuestión a destacar es que los titulares de las tarjetas son los jóvenes estudiantes; quienes tienen la posibilidad de extraer el dinero en efectivo y asumen el compromiso de asistir regularmente al nivel en que se encuentren insertos en instituciones de educación formal.
} 
largo del embarazo y en el primer año de vida del niño. El monto total asciende a $\$ 4950$, dividido en cuotas correspondientes a las dos etapas mencionadas. ${ }^{12}$

Una explicación más detallada merece el Registro Único de Beneficiarios de Programas Sociales del GCBA (RUB), creado en el año 2001. ${ }^{13}$ En él se buscaba disponer de herramientas de gestión para asegurar el cumplimiento de los principios de "eficacia, eficiencia y equidad en el otorgamiento de los beneficios" de programas los programas sociales del GCBA. ${ }^{14}$ En la práctica, lo que ocurre es que para ser receptor de un programa social de la ciudad, se torna imprescindible la visita del RUB en el domicilio que la persona declara. Allí se realiza una encuesta donde se relevan los principales datos del grupo familiar, y el profesional que realiza la visita elabora una suerte de informe social que es lo que determina en muchos casos el monto al que va a acceder el hogar receptor. Es decir que no solo la familia tiene que demostrar al momento en que se inscribe que se encuentra en situación de pobreza, sino que además el propio programa tiene que constatarlo, constituyéndose, en definitiva, como un segundo filtro de acceso y como instrumento principal de focalización. EI RUB se presenta en el domicilio de forma espontánea y sin aviso previo. En caso de no encontrarse la persona en la casa, se procede a la suspensión o la baja del grupo familiar del programa, en la presunción de que es responsabilidad de las familias demostrar que cumplen con los requisitos exigidos. Este mecanismo de certificación termina convirtiéndose en la policía de la política social de la ciudad, de la que depende el acceso o no al programa.

\section{El programa Ticket Social: Características y Procedimiento de ingreso}

A mediados de 2008, en el marco de una nueva gestión de gobierno, lejos de ampliar la cobertura de CP -abriendo su inscripción-, se instituyó un nuevo dispositivo llamado "Ticket Social", 15 incompatible con CP y destinado a la misma población objetivo, pero con un monto de prestación y de tiempo notablemente menor. ${ }^{16}$ Asimismo, la

12 línea 22-11-2015): http://www.buenosaires.gob.ar/desarrollosocial/ciudadaniaportena/programa-ciudadaniaportena/preguntas-frecuentes-salud-y-educacion.

${ }^{13}$ Decreto No 904 publicado en el Boletín Oficial de la Ciudad de Buenos Aires № 1233 del día 16 de julio del 2011.

${ }^{14}$ El objetivo era, de esta manera, concentrar de forma centralizada y unificada la información de los receptores de los distintos programas.

15 Decreto 800/08, que deroga y sustituye programas alimentarios previos a Ciudadanía Porteña como Apoyo Alimentario Directo a Familias y Vale Ciudad.

${ }^{16}$ La prestación alimentaria se otorga por seis meses, siendo condición para la renovación que el receptor haya cumplido las obligaciones a su cargo y que se encuentre dentro de los criterios de selección vigentes al momento de su renovación. Además, será responsable del efectivo destino final de los tickets y del cumplimiento de las condiciones de permanencia. Si durante el periodo de vigencia se constataran 
prestación es fija para todas las familias receptoras, independientemente de la composición y características del hogar.

Se excluye del programa a aquellos hogares que sean receptores de otros programas sociales o que superen los $\$ 1464 .{ }^{17}$ Adicionalmente, la autoridad de aplicación determinará las sanciones por incumplimiento de las obligaciones a los receptores pudiendo apercibirlos, suspenderlos o excluirlos del programa. ${ }^{18} \mathrm{~A}$ diferencia de CP, que en la práctica solo permite el ingreso de hogares con DNI y dos años de residencia en la ciudad, el titular de Ticket Social, hasta la sanción de la Ley 4036, de "Protección Integral de los Derechos Sociales", solo debía poseer algún documento (vigente) que acreditase su identidad, ser mayor de 18 años y con residencia actual en la ciudad (sin exigir cantidad de años de residencia).

El monto fijado por TS de $\$ 250$ es notablemente menor al de CP y no ha sido actualizado en tiempos recientes, según la información difundida por el GCBA. ${ }^{19}$ Este monto, sin el plus por desnutrición o celiaquía, ${ }^{20}$ apenas alcanza una fracción de la Canasta Básica Alimentaria para un adulto equivalente informada por la DGEC, que ascendía a $\$ 1678,42$ en septiembre de $2015 .{ }^{21}$ En ese mes, el monto fijado por Ticket Social solo representaba, por lo tanto, menos del $15 \%$ de la valorización del monto de la Canasta Básica Alimentaria de la CABA, para un adulto equivalente, mientras que la transferencia promedio del CP en el caso de los hogares indigentes representaba alrededor del $73,7 \%$ de ese monto. Debe añadirse que Ciudadanía Porteña posibilita ajustes por inflación al estar atado el monto a las variaciones de la Canasta Básica Alimentaria -mientras que TS sufre aumentos esporádicos que no están vinculados a la canasta básica- y contempla la existencia de asignaciones especiales en caso de integrantes de familias en situaciones específicas.

cambios en la situación social o falsedad en los datos declarados, la autoridad competente podrá dar de baja del programa, de oficio y sin más trámite, al hogar.

17 Valga decir que la Resolución No 1228/MDSGC/08 lo expresa de esa manera y no prevé ajuste por inflación. Asimismo, queda excluido quien sea titular de dos o más propiedades, automóvil modelo 2002 en adelante, receptor de programa provincial, empleados del GCBA, monotributistas que no sean categoría A o monotributistas sociales.

${ }^{18}$ Los receptores del Ticket Social están obligados a presentar certificado médico del integrante con riesgo nutricional cada seis meses, informar todas las modificaciones del grupo familiar conviviente relativo a ingresos, cambio de domicilio o cualquier modificación, dentro de los 30 días de producida, entre otras cosas.

${ }^{19}$ En línea (acceso 22-11-2015): http://www.buenosaires.gob.ar/desarrollosocial/ciudadaniaportena/ticket$\underline{\text { social }}$

20 En los casos en que los grupos familiares estén constituidos con algún integrante que presente desnutrición o celiaquía se le entrega una chequera adicional por el $50 \%$ del monto que se le dio originalmente (es decir, no se contemplan otras enfermedades crónicas que requieran una alimentación acorde ej.: H.I.V., hepatitis, diabetes).

${ }^{21}$ Cfr. Canastas de consumo de la Ciudad de Buenos Aires, octubre de 2015, DGEC. 
De esta manera, se evidencia la diferencia de tratamiento para hogares que presentan las mismas condiciones de vulnerabilidad. El Estado supone que los hogares receptores del Ticket Social pueden satisfacer sus derechos más básicos, como el derecho a la alimentación, con tan solo $\$ 250$ mensuales por grupo familiar. Se debe tener en cuenta que una parte importante de los hogares receptores de TS cumplen con los requisitos para ingresar a $\mathrm{CP}$, pero que no son incorporados en tiempo oportuno obligándolos a subsistir con un monto insuficiente.

\section{El cierre de inscripción directa a Ciudadanía Porteña y del ingreso a este programa través del traspaso de hogares receptores de Ticket Social a la luz del derecho a la alimentación en el sistema internacional y regional de derechos humanos}

El enfoque de derechos humanos funciona como guía a un conjunto de principios que se desprenden del derecho internacional de los Derechos Humanos y que resultan útiles en tanto orientan el desarrollo de las políticas. Constituyen parámetros relativamente objetivables para conformarse en estándares aplicables a las políticas existentes y demostrar la distancia -o no-entre estas y el enfoque. Los Estados se han comprometido a dar cumplimiento al derecho a la alimentación a través de numerosos tratados de derecho internacional de los derechos humanos, como parte integrante del derecho a un nivel de vida adecuado. El Comité DESC -órgano supervisor de las obligaciones emanadas del Pacto internacional de derechos económicos, sociales y culturales (PIDESC)-, ha determinado en su Observación General № 12 (1999), la definición y el contenido mínimo del derecho a la alimentación. Comprende que la alimentación debe ser adecuada, debe estar disponible (esta debe ser en cantidad y calidad suficientes para satisfacer las necesidades alimentarias de los individuos, libres de sustancias nocivas, y en formas aceptables para una cultura determinada) y accesible económica y físicamente. Esto último debe darse en formas que sean sostenibles y que no dificulten el goce de otros derechos humanos (Comité DESC 1999). Es importante destacar que este derecho se encuentra íntimamente relacionado con el derecho a la vida, a la salud, al agua, a la vivienda adecuada, a la educación, al trabajo, entre otros. Para garantizar la accesibilidad, los Estados deben prestar especial atención y, en ciertos casos, conceder prioridad con respecto a la accesibilidad de los alimentos a las personas que viven en zonas propensas a los desastres y a otros grupos particularmente desfavorecidos (Comité DESC 1999). El hecho de ser titular de un derecho habilita a cada persona al acceso a mecanismos de reclamo que le permita exigir la efectividad de los derechos humanos ante cualquier violación. Las vías y mecanismos para hacer efectivos los derechos deben ejercerse ante los organismos y autoridades competentes, ya sean políticas, administrativas 0 judiciales. Específicamente, el Comité DESC (1998: 7) ha resaltado la importancia de "tener en cuenta la necesidad de asegurar la justiciabilidad" de los DESC. Esto es, la posibilidad 
de denunciar la violación de un derecho o exigir su restitución ante la justicia, cuestión que está condicionada a la existencia de normas que permitan llevar estas demandas a los tribunales y que la decisión que se adopte sea efectivamente implementada. Al respecto, la Directriz 1.4 de la FAO establece que los Estados deben velar por que se conceda a todas las personas, incluidos los defensores de los derechos humanos y la realización progresiva del derecho a una alimentación adecuada, igual protección jurídica y que en todos los procedimientos judiciales se apliquen las debidas garantías procesales. Dentro de este marco de protección internacional del derecho a la alimentación, no debe omitirse que Argentina ha suscripto los principales instrumentos internacionales de derechos humanos mencionados. Por lo tanto, la Ciudad Autónoma de Buenos Aires se encuentra obligada a garantizar dichos derechos. Particularmente, en su Constitución se garantiza el derecho a la alimentación como parte integrante del derecho a la salud.

En relación con ello, como se ha desarrollado previamente, el ingreso directo al programa CP se encuentra cerrado. Desde el último operativo de inscripción en 2006, el ingreso al programa se dio a través del traspaso desde el programa AADF (cajas) y desde el 2008 a la actualidad, a través del ingreso al programa TS. ${ }^{22}$ Sin perjuicio de ello, la ex Ministra de Desarrollo Social, María Eugenia Vidal, ${ }^{23}$ declaró que el programa Ciudadanía Porteña no se encuentra cerrado, sino que, como la incorporación de hogares lleva tiempo, ante la necesidad de cumplimentar una serie de pasos vinculados con el estudio del estado de necesidad de los hogares, se los incorpora, en primera instancia, a Ticket Social. ${ }^{24}$

A pesar que la Dirección General de Ciudadanía Porteña informa que el procedimiento de traspaso demora entre 30 y 60 días, se presentan demoras injustificadas en el traslado de un hogar desde un programa a otro $y$, en la realidad, el traspaso puede efectivizarse, en muchos casos, en plazos cercano a un año. ${ }^{25}$ Este retraso tiene una importante consecuencia: los grupos familiares permanecen cobrando Ticket Social y su monto insuficiente vulnera un conjunto de derechos, entre ellos el de la alimentación.

\footnotetext{
${ }^{22}$ Valga aclarar también que el TS es incompatible con CP.

${ }^{23}$ Fuente: Versión taquigráfica de la reunión de la Comisión de Presupuesto, Hacienda, Administración Financiera y Política Tributaria. 21 de octubre de 2009, realizando la presentación del presupuesto 2010.

24 En octubre de 2011, la ministra, en el marco de la reunión de la Comisión de Presupuesto de la Legislatura, en la presentación del presupuesto 2012, expresó: "No es que el ingreso a Ciudadanía Porteña se haga a través del Programa Ticket; puede hacerse sin este programa. Lo que pasa es que el Programa de Ciudadanía Porteña tiene dos instancias de evaluación para el acceso. (...) Eso lleva un tiempo".

${ }^{25}$ Esta información proviene de la acción judicial presentada por el Ministerio Público Tutelar.
} 
Teniendo en cuenta que el diseño del programa no permite el acceso en un plazo razonable al Programa Ciudadanía Porteña de toda familia receptora de Ticket Social que así lo solicite, el Ministerio Público Tutelar (MPT) de la Ciudad de Buenos Aires ${ }^{26}$ presentó en junio de 2012 una acción judicial poniendo de relieve que, durante el tiempo que las personas esperan el acceso, no perciben el monto necesario para hacer efectivo su derecho a la alimentación. Este amparo colectivo presentado aún se encuentra en trámite.

El objetivo perseguido por dicha acción fue que se ordenase al GCBA cumplir con su obligación constitucional de garantizar el derecho a la salud integral, a la alimentación, a la igualdad y a la autonomía personal de todos los niños, niñas, adolescentes y personas con padecimientos mentales que solicitasen las prestaciones previstas en los programas alimentarios de la Ciudad de Buenos Aires. Particularmente, se peticionó la inclusión en un plazo razonable al programa CP de todas las personas que así lo solicitasen. Mientras se diese dicha inclusión, se solicitó que, para aquellas personas receptoras de TS, se ordenase la adecuación del monto de la prestación obtenida, como mínimo, a las pautas previstas en $\mathrm{CP}$, hasta tanto se hiciese efectivo el acceso a este último. Es menester señalar que en esta acción se cuestiona puntualmente la política alimentaria en tanto no garantiza el derecho en un plazo razonable para todos los casos, y brinda recursos claramente insuficientes para subsanar esta situación. Acorde a la medida cautelar de julio de 2013, se ordena al GCBA que reglamente la Ley 1878, que creó $C P$, específicamente el procedimiento para la selección de los/as aspirantes. Asimismo, y en relación con TS, ordena el establecimiento de criterios de distinción de hogares receptores que permitan que la prestación otorgada guarde relación con la integración del hogar. Así como también ordena una instancia o pauta de actualización periódica obligatoria del monto de los beneficios. ${ }^{27}$

El GCBA apeló el caso fundado en la representación de quien presentó el caso y, en base a este argumento formal, la sentencia fue revocada.

En este sentido, la sentencia de primera instancia abrió la reflexión en torno al impacto que puede tener la presentación de una acción judicial en relación con el derecho a la alimentación, sin embargo, esta situación cambió dos años después con el reciente fallo que revoca la sentencia.

\footnotetext{
${ }^{26}$ El Ministerio Público Tutelar es una institución que integra el Poder Judicial de la Ciudad Autónoma de Buenos Aires. Su misión principal es promover la justa aplicación de la ley, la legalidad de los procedimientos y el respeto, la protección y la satisfacción de los derechos y garantías de los niños, niñas y adolescentes y de las personas afectadas en su salud mental.

27 Fallo disponible en: https://www.jusbaires.gob.ar/sites/default/files/amparo-asesoria-tutelar-y-acijcuestionan-aspectos-de-ciudadania-portena-y-ticket-social-exp-44701.pdf (última consulta: 10 de julio de 2015).
} 


\section{Un análisis cuantitativo del desempeño de los programas de seguridad alimentaria de la Ciudad Autónoma de Buenos Aires}

En esta sección se analizará el desempeño de las políticas de promoción del derecho a la alimentación ejecutadas por el Gobierno de la Ciudad Autónoma de Buenos Aires (GCBA) desde un punto económico y cuantitativo, utilizando la información extraída de estadísticas oficiales. ${ }^{28}$ En primer lugar, se tratará de la cobertura horizontal de la política, es decir, el número de hogares atendidos por los programas alimentarios del GCBA. En segundo lugar, se discutirá sobre la extensión vertical de estos programas, estimando la evaluación en términos reales de los montos de las transferencias y el grado en que estas logran cubrir las canastas alimentarias básicas. Junto con las canastas del INDEC y las proporcionadas por la Dirección General de Estadística y Censos (DGEC) de la CABA (Canasta Alimentaria, CA-Ciudad, años varios), se propone una Canasta Básica Alimentaria (CBA) revalorizada según un índice de precios al consumo de alimentos y bebidas (IPCA4p) obtenido de una elaboración de los datos proporcionados por provincias del interior. Como se dijo, para empezar, se presentarán datos que hacen a la extensión horizontal de los programas, en el periodo posterior a la implementación del CP. Las cuentas de inversión, que contienen información relativa al presupuesto efectivamente realizado, muestran la evolución de los hogares que fueron atendidos por estos programas entre 2006 y 2012. Se trata de las metas físicas que fueron realizadas en el año de ejercicio de referencia. Para simplificar, los datos de la denominada "Ciudadanía Joven" -o "Estudiar es trabajar"-, fueron sumados a los del programa general CP. Además, se incluyen los datos de TS -anteriormente, "programa de seguridad alimentaria", PSA-, en cuanto, como se vio en otras secciones, constituye la antesala de ingreso a CP. Los resultados de esta elaboración pueden observarse en la Tab. 2.

Tabla 1. Hogares atendidos en los programas de promoción del derecho a la seguridad alimentaria.

\begin{tabular}{|l|lllllll|}
\hline Hogares/año & 2006 & 2007 & 2008 & 2009 & 2010 & 2011 & 2012 \\
\hline CP & 47.246 & n.d. & 67.517 & 72.441 & 67.370 & 62.000 & 56.880 \\
PSA/TS & 60.094 & n.d. & 11.066 & 18.358 & 18.613 & 28.656 & 31.276 \\
\hline Total & 107.340 & 97.438 & 78.583 & 90.799 & 85.983 & 90.656 & 88.156 \\
\hline $\begin{array}{l}\% \text { total hogares } \\
\% \quad \text { hogares }\end{array}$ & $9,05 \%$ & $8,01 \%$ & $6,43 \%$ & $7,48 \%$ & $6,91 \%$ & $7,43 \%$ & n.d. \\
pobres & $32,21 \%$ & n.d. & $26,69 \%$ & $30,18 \%$ & $27,78 \%$ & $31,86 \%$ & n.d. \\
& & & 178,69 & 174,05 & 136,52 & 219,04 & \\
$\%$ indigentes & $220,76 \%$ & n.d. & $\%$ & $\%$ & $\%$ & $\%$ & n.d. \\
\hline
\end{tabular}

\footnotetext{
${ }^{28}$ En particular, se hará referencia a las cuentas de inversión de la CABA (Cfr. Contaduría General, años varios) y los Informes de Monitoreo y Evaluación del Ministerio de Desarrollo del GCBA (Cfr. GOGEPS, años varios).
} 
Fuente: Elaboración propia sobre datos de las Cuentas de Inversión del Gobierno de la Ciudad Autónoma de Buenos Aires, años varios. En algunos años, se estima el $n^{\circ}$ de hogares de cada programa con los Informes de Monitoreo. El $n^{\circ}$ de hogares pobres (ingresos por debajo de la Canasta Total) e indigentes (por debajo de la Canasta alimentaria), derivan de CEDEM (2012), donde se utiliza el sistema de canastas de la CABA.

Una mirada a la información que consta en la tabla permite formular algunas observaciones preliminares respecto del desempeño de los programas. En primer lugar, se observa una reducción de la población atendida por los programas de la ciudad. No existe una correlación con la evolución de la población objetivo, en particular, los indigentes. En este sentido, no se trata de una política anticíclica, ya que en los años en los que la economía argentina fue afectada por la crisis internacional y la Dirección General de Estadística y Censos registró un incremento de los hogares pobres e indigentes (2009 y 2010, en particular), no se registra un incremento constante de la cobertura de los dos programas analizados. Naturalmente, esto podría ser debido a la implementación de la Asignación Universal por Hijo ${ }^{29}$ a finales de 2009. En todo caso, las cifras sugieren que se trata de un programa residual, muy focalizado hacia los sectores indigentes de la población, cuya prestación resulta fijada, como se verá a continuación, en un nivel suficientemente bajo para no interferir en los incentivos de mercado de los receptores, según un diseño de tipo liberal (cfr. por ej. EspingAndersen, 1993). Los datos más recientes -mayo 2015- confirman que la tendencia se ha mantenido, ya que el GCBA informa que en ese momento la cantidad de hogares receptores ascendía a 49085, de los cuales 31073 se encontraban en situación de pobreza y 18012 en situación de indigencia.

Tabla 2. Una comparación entre Ciudadanía Porteña y las canastas alimentarias. ${ }^{30}$

\begin{tabular}{|l|l|l|l|l|l|l|}
\hline \multicolumn{2}{|l|}{ Años } & 2008 & 2009 & 2010 & 2012 & 2013 \\
\hline En \$ & Monto Promedio & 363,4 & 366,7 & 383,5 & 692,61 & 778,5 \\
\hline
\end{tabular}

\footnotetext{
${ }^{29}$ La Asignación Universal por Hijo es un subprograma no contributivo dentro del régimen nacional de Asignaciones Familiares, el cual consiste en una transferencia mensual por cada niña o niño hasta los 18 años o sin límite de edad en caso de ser discapacitado, a las familias cuyos padres se encuentren desempleados, sean trabajadores informales o monotributistas sociales. La transferencia se realiza a la madre y está sujeta a condicionalidades educativas y de salud, constituyendo a la AUH como un híbrido entre los PTCI y el régimen de la seguridad social, como lo han indicado distintos autores (cfr. Pautassi et al. 2013). Es, en la actualidad, el programa nacional de mayor alcance y cobertura, con más de 3,5 millones de niños incluidos dentro de la AUH.

${ }^{30}$ Se hace referencia a canasta alimentaria del adulto equivalente, es decir al precio de adquirir los bienes alimentarios necesarios para cubrir las necesidades calóricas de un hombre adulto entre 30 y 59 años. Si estas se igualan a la unidad, las tablas de equivalencia permiten calcular las necesidades calóricas de personas con diferentes características fisiológicas, según su sexo y edad. En el caso del INDEC se hace referencia a Morales (1988). En el caso de la CABA, se utiliza la tabla de equivalencias del sistema de canastas de consumo de la DGEC.
} 


\begin{tabular}{|l|l|l|c|c|c|c|}
\hline & Hogares indigentes & n.d. & 442,1 & 467 & 830,72 & 954,5 \\
\cline { 2 - 7 } & Hogares pobres & n.d. & 314,3 & 339,8 & 616,21 & 678,5 \\
\cline { 2 - 7 } & CA (IPCA-4p) & 333,1 & 347,4 & 404,9 & 777,2 & 960,9 \\
\hline \multirow{2}{*}{$\begin{array}{l}\text { CP en \% de } \\
\text { la }\end{array}$} & Promedio & $\begin{array}{c}109,10 \\
\%\end{array}$ & $\begin{array}{c}105,60 \\
\%\end{array}$ & $94,70 \%$ & $89,10 \%$ & $\begin{array}{c}81,02 \\
\%\end{array}$ \\
\cline { 2 - 7 } & Hogares indigentes & n.d. & $\begin{array}{c}127,30 \\
\%\end{array}$ & $\begin{array}{c}115,30 \\
\%\end{array}$ & $\begin{array}{c}106,90 \\
\%\end{array}$ & $\begin{array}{c}99,33 \\
\%\end{array}$ \\
\cline { 2 - 7 } & Hogares pobres & n.d. & $90,50 \%$ & $83,90 \%$ & $79,30 \%$ & $\begin{array}{l}70,61 \\
\%\end{array}$ \\
\hline
\end{tabular}

Fuentes: Informes de Monitoreo Ciudadanía Porteña y Estudiar es Trabajar Ene-2014; Dic-2012; Ene-2010; May-2009; Dic-2008 (Cfr. GOGEPS). Canasta Alimentaria (adulto equivalente), base DGES GCBA, Dic 2005: $\$ 197,2$, actualizada con IPC4p.

En lo que respecta al grado en que las prestaciones del programa Ciudadanía Porteña logran cubrir las necesidades alimentarias básicas de los receptores, ${ }^{31}$ se comparó la evolución del monto promedio de las prestaciones erogadas en el ámbito de Ciudadanía Porteña con la evolución de la Canasta Alimentaria, ${ }^{32}$ distinguiendo además entre la situación de los hogares pobres y los indigentes, ya que el nivel de la prestación está modulado según los niveles de necesidad del hogar receptor. Como puede verse en la Tabla 2, en 2013 (abril), la prestación promedio cubría apenas la CAIPC4p. Considerando que la CA oficial de la Ciudad es incluso menor, estos datos mostrarían que las prestaciones erogadas por el gobierno porteño han ido perdiendo eficacia en el objetivo de cubrir por lo menos las necesidades básicas alimentarias de los hogares más necesitados. Debe considerarse, además, que los hogares receptores están distribuidos de forma que una mayoría está recibiendo una prestación cuyo valor es inferior al promedio. Por ejemplo, según el informe de monitoreo de octubre de 2014 en septiembre de ese año el 33\% cobró hasta $\$ 600$ y un 52\% de ellos cobraron una prestación menor a $\$ 900$ (contra una prestación promedio de $\$ 1022$ en ese mes). Considerando que las familias con ingresos inferiores a la CA suelen estar caracterizadas por un número medio de componentes superior al promedio general de la población, y con un número mayor de personas dependientes, especialmente

\footnotetext{
${ }^{31}$ El programa TS, como se vio, prevé una prestación muy reducida, por lo que el razonamiento aplicado a $\mathrm{CP}$ tiene una validez aún mayor.

32 La metodología utilizada en este trabajo, por las razones aducidas por Lindenboim (2011), utiliza una canasta alimentaria que hace referencia al costo de los consumos básicos en la Ciudad de Buenos Aires (CA-Ciudad). Sobre la base de Barbeito (2010), en este trabajo se utiliza un promedio simple del índice de precios de alimentos y bebidas de cuatro provincias (IPCA4p), San Luis, Santa Fe, Neuquén y La Pampa para actualizar la CA-Ciudad, mes a mes, tomando como valor inicial de la serie el valor publicado por la DGEC-CABA en noviembre de 2005 (\$195).
} 
niños/as, esta reducción del alcance del programa contribuye a la desprotección de los sectores más vulnerables. De hecho, analizando los datos de los informes de monitoreo, es posible calcular que, a lo largo del periodo considerado entre un $46 \%$ y un $48 \%$ de la población atendida por CP era menor de 18 años, y entre un 30\% y un 34\% menor de 12 años (DGEC).

Un factor que explica esta evolución negativa es el insuficiente nivel de incremento del presupuesto destinado a los programas de protección del derecho a la seguridad alimentaria. Como puede verse en la Tab. 3, pese al notable crecimiento de las partidas destinadas a los programas de seguridad alimentaria (TS y CP) en términos nominales, ese crecimiento desaparece -e incluso disminuye- si se calculan las mismas variaciones en términos reales, sobre la base de la variación de precios a nivel de provincias. ${ }^{33} \mathrm{Si}$ se recalculan las variaciones a partir de 2008 (cuando empieza la responsabilidad de la actual gestión), estos rasgos resultan todavía más notables: mientras que el presupuesto real ejecutado bajo CP disminuye en torno a un $45 \%$ entre 2008 y 2012, el que hace referencia a TS es incrementado un $73 \%$ aproximadamente.

Tabla 3. Variación anual del presupuesto destinado a programas de seguridad alimentaria (nominal y real-pesos de Dic-2006).

\begin{tabular}{|c|c|c|c|c|c|c|c|}
\hline Años & 2007 & 2008 & 2009 & 2010 & 2011 & 2012 & $\begin{array}{l}\text { Variación } \\
\text { entre } \\
\text { puntas }\end{array}$ \\
\hline \multicolumn{8}{|l|}{ Variación nominal } \\
\hline \multirow[t]{2}{*}{$\mathrm{CP}$} & $108,53 \%$ & $29,36 \%$ & $7,69 \%$ & $7,15 \%$ & $25,60 \%$ & $12,30 \%$ & $339,05 \%$ \\
\hline & & & 51,79 & & & & \\
\hline PSA/Ticket Social & $-50,30 \%$ & $90,76 \%$ & $\%$ & $36,14 \%$ & $26,61 \%$ & $28,55 \%$ & $218,84 \%$ \\
\hline Total & $84,68 \%$ & $30,10 \%$ & $9,91 \%$ & $10,08 \%$ & $25,86 \%$ & $15,04 \%$ & $320,88 \%$ \\
\hline \multicolumn{8}{|l|}{ Variación real } \\
\hline & & & & & & - & \\
\hline \multirow[t]{2}{*}{$C P$} & $61,72 \%$ & $0,82 \%$ & $-9,22 \%$ & $-20,67 \%$ & $-4,67 \%$ & $12,89 \%$ & $-2,49 \%$ \\
\hline & & & 27,95 & & & & \\
\hline \multirow[t]{2}{*}{ PSA/Ticket Social } & $-61,46 \%$ & $48,67 \%$ & $\%$ & $0,79 \%$ & $-3,90 \%$ & $-0,29 \%$ & $-29,18 \%$ \\
\hline & & & & & & - & \\
\hline Total & $43,23 \%$ & $1,40 \%$ & $-7,35 \%$ & $-18,50 \%$ & $-4,47 \%$ & $10,77 \%$ & $-6,52 \%$ \\
\hline
\end{tabular}

Fuente: Cuentas de Inversión del Gobierno de la Ciudad Autónoma de Buenos Aires (Contaduría General); elaboración propia sobre datos de INDEC; Direcciones provinciales de Estadística y Censos (Neuquén, San Luis, Santa Fe, La Pampa); DGEC-CABA; Informes de Monitoreo Ciudadanía Porteña, años varios (GOGEPS).

Estos resultados negativos son confirmados si se calculan las variaciones del presupuesto promedio por hogar, para incluir en el análisis la variación observada en el número de hogares atendidos. Como se vio, en el periodo considerado, el número de hogares atendidos por los programas de seguridad alimentaria se redujeron en casi un

\footnotetext{
33 A partir de agosto 2012, la DGEC de la CABA publica una serie de precios propia, cuya evolución se acerca a la calculada sobre la base de las variaciones de precios en las provincias del interior.
} 
18\%. Esta variación fue causada por una reducción del $48 \%$ de los hogares receptores de programas PSA/Ticket Social, que no fue compensada por el incremento del $20 \%$ de los hogares incluidos en CP, entre 2006 y 2012. A partir de estas consideraciones, es posible calcular que el gasto por hogar en políticas de seguridad alimentaria creció solo en un $13 \%$ en el arco de seis años. Sin embargo, el programa más importante de la ciudad, $C P$, sufrió una reducción considerable del gasto por hogar en el mismo periodo, es decir una caída del $19 \%{ }^{34}$

En conclusión, en esta sección se efectuó un análisis cuantitativo de la información oficial relacionada con los programas de seguridad alimentaria de la CABA, en particular, el denominado Ciudadanía Porteña. Los resultados muestran una reducción de la cobertura de estos programas, que podría ser causada por la implementación a nivel nacional de la Asignación Universal por Hijo para Protección Social (AUH). Además, la reducción del esfuerzo de gasto en estos programas, que se refleja en particular en la caída en términos reales del programa de transferencia más importante, Ciudadanía Porteña, explicaría el bajo desempeño en términos de necesidades básicas alimentarias cubiertas. Este último elemento fue analizado por medio de una comparación entre el promedio de las prestaciones y una estimación de las canastas alimentarias básicas mensuales a lo largo del periodo analizado.

\section{Reflexiones finales}

El foco de este trabajo fue el análisis de dos de los principales programas alimentarios que se implementan en la actualidad en la Ciudad de Buenos Aires, Ciudadanía Porteña y Ticket Social. Como se mencionó en la introducción, la ciudad es el distrito más rico, al mismo tiempo que el más desigual del país. Se presentan aquí características compartidas por otras grandes urbes latinoamericanas, alta densidad poblacional debido a que es en la capital donde se concentran en mayor medida las oportunidades laborales. Asimismo, la CABA presenta una constitución local con un amplio reconocimiento de derechos, en línea con la constitución nacional que, a partir de su última reforma en el año 1994, incorporó una serie de tratados y pactos internacionales de derechos humanos, otorgándoles jerarquía constitucional, es decir, abriendo el marco para su exigibilidad.

A lo largo de la investigación presentada en este trabajo se vio cómo Ciudadanía Porteña fue un programa innovador y de ampliación de derechos al momento de su creación, superando problemas de programas anteriores, ampliando los niveles de cobertura y de impacto dentro de la población más vulnerable de la ciudad, sin escapar, por cierto, de los problemas y críticas propias que presentan todos los PTCI que se han implementado en la región. Sin embargo, con el correr de los años y con las

\footnotetext{
${ }^{34}$ El gasto por hogar de PSA/TS se incrementó en un 36\%, principalmente por la fuerte reducción de los hogares atendidos en comparación a 2006, aunque a partir de 2008, con la nueva gestión, se observa un incremento de los receptores de TS.
} 
nuevas gestiones de gobierno, el rumbo parece haber cambiado, ya que no se ha profundizado la implementación de $\mathrm{CP}$, ampliándolo y 'mejorándolo', sino que se creó un programa con las características de Ticket Social, cuyo objetivo es la misma población vulnerable y con requisitos de acceso similares, pero que da derecho a una prestación de monto irrisorio, en primer lugar, porque es mucho menor al de CP y, en segunda instancia, porque no tiene relación alguna con los requerimientos mínimos de la canasta alimentaria. Por todo lo dicho, la respuesta al derecho a la alimentación que las políticas del GCBA da es por lo tanto deficitaria, y sin lugar a dudas representa una transformación regresiva en relación con el piso mínimo logrado en años anteriores. Puede afirmarse esto, sobre todo a la luz de lo que cuesta en términos simbólicos, materiales y de tiempo a las familias receptoras pasar de un programa a otro. Es, por lo tanto, desde esta perspectiva de derechos que fueron analizadas las políticas alimentarias de la ciudad, es decir, discutiendo en cada ámbito si constituyen un avance o un retroceso frente al derecho a la alimentación.

El análisis cuantitativo que concluye este trabajo no hace sino confirmar estos resultados, ya que muestra cómo, en términos reales, el esfuerzo fiscal del GCBA a favor del que era el más 'progresivo' de los dos programas analizados fue disminuyendo a lo largo de los últimos ejercicios. Se analizó, en particular, el impacto de los mencionados programas, para ver su evolución a lo largo de los años, su impacto y los retrasos en la actualización de los montos en relación con los cambios en las canastas alimentarias debido al contexto de elevada inflación. Los resultados muestran una reducción continua de la población cubierta por estos programas, hecho debido a al descenso de la cobertura de Ciudadanía Porteña -mientras que el número de receptores de Ticket Social aumentó desde su implementación-, aunque es posible que este dato esté relacionado con la implementación a nivel nacional de la AUH. Además, cabe destacar la reducción en términos reales del gasto destinado a estos programas, en particular para el caso de Ciudadanía Porteña, lo que explicaría el bajo desempeño en términos de necesidades básicas alimentarias cubiertas. Debe subrayarse nuevamente que si se recalculan las variaciones a partir de 2008 (cuando empieza la responsabilidad de la actual gestión), mientras que el presupuesto real ejecutado bajo CP disminuye en torno a un 45\% entre 2008 y 2012, el que hace referencia a TS es incrementado un 73\% aproximadamente. Este aspecto explica cómo las transferencias erogadas por la ciudad son insuficientes para garantizar de forma adecuada el derecho a la alimentación de los receptores, como fue evidenciado con la comparación entre el promedio de las prestaciones y una estimación de las canastas alimentarias básicas mensuales a lo largo del periodo analizado.

Frente a esta situación y a la persistencia de las situaciones de pobreza e indigencia en la ciudad, adquieren especial interés las demandas sociales de mayor protección del derecho a la alimentación que han sido vehiculizadas en el caso porteño también en instancias del poder judicial. En esta línea es que también se ha analizado la 
presentación de una acción de amparo por parte de la Asesoría General Tutelar (AGT), en tanto el Poder Judicial juega un rol clave en la arena de las políticas públicas para exigir el efectivo cumplimiento de los derechos sociales. Este caso representa uno de los ejemplos más interesantes de judicialización del derecho a la alimentación que se han dado en Argentina, pero cuyo interés transciende las fronteras de este país.

\section{Referencias}

Asesoría General Tutelar (2011). Programa Ciudadanía Porteña ¿con todo derecho? Fortalezas y debilidades de las transferencias monetarias condicionadas focalizadas en niños, niñas y adolescentes. Buenos Aires: Eudeba.

Barbeito, Alberto (2010). Re-construcción de índices de precios al consumidor y su incidencia en la medición de algunas variables monetarias reales. Análisis de Coyuntura, No. 23, Buenos Aires, CIEPP.

Cecchini, Simone y Madariaga, Aldo (2011). Programas de Transferencias Condicionadas: balance de la experiencia reciente en América Latina y el Caribe". Cuadernos de La CEPAL 95.

CEDEM - Centro de Estudios para el Desarrollo Económico Metropolitano (2012). Condiciones de vida en la Ciudad de Buenos Aires. Un análisis a partir del Sistema de Canastas de Consumo, 2005-2010, Buenos Aires, Ministerio de Hacienda (Gobierno de la Ciudad de Buenos Aires).

Comité DESC (1998). Observación general № 9, La aplicación interna del Pacto, 19 período de sesiones.

Comité DESC (1999). Observación general $N^{0} 12$, El derecho a una alimentación adecuada (artículo 11), $20^{\circ}$ período de sesiones.

Organización de las Naciones Unidas para la Alimentación y la Agricultura

Roma (2005), DIRECTRICES VOLUNTARIAS en apoyo de la realización progresiva del derecho a una alimentación adecuada en el contexto de la seguridad alimentaria nacional, Consejo de la FAO, $127^{\circ}$ período de sesiones, noviembre

Contaduría General (años varios) Cuentas Anuales de Inversión, Buenos Aires, Ministerio de Hacienda (Gobierno de la Ciudad de Buenos Aires).

DGEC - Dirección General de Estadística y Censos (años varios) Informes de Resultados Canastas de Consumo de la Ciudad de Buenos Aires. Ministerio de Hacienda, Gobierno de la Ciudad de Buenos Aires.

Esping-Andersen, Gøsta (1993). Los tres mundos del Estado del Bienestar. Valencia: Alfons el Magnanim.

Gerencia Operativa de Gestión Estratégica de Políticas Sociales (GOGEPS) (años varios) Informes de Monitoreo y Evaluación de Programas Sociales, Buenos Aires, Ministerio de Desarrollo Social (Gobierno de la Ciudad de Buenos Aires). 
Lindenboim, Javier (2011). Las estadísticas oficiales en Argentina ¿Herramientas u obstáculos para las ciencias sociales? Trabajo y Sociedad, vol. XV, N. ${ }^{\text {ro }} 16,19-38$.

Morales, Elena (1988). Canasta básica de alimentos - Gran Buenos Aires. Documento de trabajo, N. ${ }^{\text {ro }}$ 3, Buenos Aires, INDEC/IPA.

Observación General No 12 (1999),

Pautassi, Laura y Zibecchi, Carla (2009). "La provisión de cuidado y la superación de la pobreza infantil. Programas de transferencias condicionadas en Argentina y el papel de las organizaciones sociales y comunitarias". Documento preparado para la Iniciativa CEPAL/UNICEF en América Latina y el Caribe: Pobreza infantil, desigualdad y ciudadanía". Santiago de Chile, agosto 2009.

Pautassi, Laura, Arcidiácono, Pilar y Straschnoy Mora, (2013). Asignación Universal por Hijo para la Protección Social de la Argentina: entre la satisfacción de necesidades y el reconocimiento de derechos". Serie Políticas Sociales 184. Santiago de Chile: CEPAL.

Rodríguez Enriquez, Corina (2011). Programas de transferencias condicionadas de ingreso e igualdad de género ¿Por dónde anda América Latina? Santiago de Chile: CEPAL.

Zibecchi, Carla (2008). Programas de transferencia de ingresos. ¿Más condicionalidades y menos derechos para madres pobres? Un análisis en base a tres experiencias en América Latina". Revista Aportes Andinos No 21. 